\title{
Effect of Earthquake on the Landscape of Jiuzhaigou-Huanglong Travertine and Its Restoration
}

\author{
F. Dong ${ }^{(\bowtie)}$, Q. Dai, Q. Li, F. Wang, and Y. Luo \\ Key Laboratory of Solid Waste Treatment and Resource Recycle, \\ School of Environment and Resource, Southwest University of Science \\ and Technology, Mianyang, People's Republic of China \\ fqdong2004@163.com
}

\begin{abstract}
The hydrogeology and hydrochemistry-calcium characteristics, microbial community changes, and dam structure geophysical exploration for the core heritage sites of Jiuzhaigou after the " 8.8 " earthquake were investigated and analyzed. The results indicated that the hydrogeology has undergone significant changes, especially the Nuorilang Waterfall and the Sparkling Lake. The surface hydrodynamic balance has been broken by the earthquake, which may cause a chain reaction such as travertine deposition, travertine erosion, and microbial community change. The Nuorilang Waterfall/Sparkling Lake dam and the cascade waterfall are seriously affected by the earthquake. The results of the profile study and geophysical exploration show that the surface fissures, cracks, subsidence pipes, and other potential geological disasters are significant. The risk of secondary collapse of the dam body and the cascade waterfall is high. It also shows that the plant and microbes in Jiuzhaigou travertine participate in higher deposition than Huanglong. The monitoring results show that both Jiuzhai and Huanglong have extremely high levels of prokaryotic and eukaryotic algae, and Jiuzhaigou is higher than Huanglong. It is suggested that on the basis of scientific argumentation, scientific restoration of the slope and dam break of the Sparkling Lake damage will be carried out so that the original water storage function of the Spark Sea will be restored as soon as possible. Finally, the Nuorilang Waterfall and Sparkling Lake Conservation Remediation Plan were proposed and part of demonstration implementations was carried out.
\end{abstract}

Keywords: Jiuzhai earthquake - Travertine hydrogeology •

Algae community $\cdot$ Hydrochemical characteristics $\cdot$ Geophysical exploration 
Open Access This chapter is licensed under the terms of the Creative Commons Attribution 4.0 International License (http://creativecommons.org/licenses/by/4.0/), which permits use, sharing, adaptation, distribution and reproduction in any medium or format, as long as you give appropriate credit to the original author(s) and the source, provide a link to the Creative Commons license and indicate if changes were made.

The images or other third party material in this chapter are included in the chapter's Creative Commons license, unless indicated otherwise in a credit line to the material. If material is not included in the chapter's Creative Commons license and your intended use is not permitted by statutory regulation or exceeds the permitted use, you will need to obtain permission directly from the copyright holder.



